ISAHP 1996, Vancouver, Canada, July 12-15, 1996

\title{
THE SELECTION OF FORECASTING METHODS AND SOFTWARE WITH THE AHP
}

\author{
Karl Weber \\ University of Giessen, D-35394 Giessen, Germany
}

\begin{abstract}
The study describes the selection of forecasting methods and software with special reference to Expert Choice for Windows, Version 9.0.
\end{abstract}

\section{AHP Approach}

\subsection{Guidelines}

The general approach to using the AHP methodology consists of five phases which can be briefly characterized as follows:

- Development of the hierarchical structure for the decision problem.

- Determination of local priorities among the decision criteria in the hierar-

chy.

- Determination of global priorities with respect to the top element of the entire hierarchy (goal).

- Consistency checking and/or sensitivity analysis of the judgements.

- Final ranking of the alternatives under investigation and decision making based on the results of the evaluation process.

Some preliminary steps involve the

- selection of AHP experts

and the

- formation of project teams assuring management cooperation and support.

The aforementioned guidelines can be refined in various ways. In many cases it will be absolutely necessary to organize

- special seminars

to acquaint the participating practitioners with the AHP methodology in general and relevant details concerning the determination of the $L$ (local) and G (global) priorities.

\subsection{Practice}

With respect to the evaluation of forecasting methods and software

- compact refresher courses

can offer a comprehensive view of AHP with special reference to the relevant measurement techniques (relative/absolute measurement).

As to the

- AHP software

a decision in favour of versatile and user friendly packages has to be made. In the current case study

- Expert Choice for Windows, Version 9.0

has been used. 


\section{Evaluation of Forecasting Methods}

The proposed evaluation program is characterized by the inclusion of a - large number of alternatives.

The evaluation process consists of several phases which encompass the - selection and hierarchization of the evaluation criteria

followed by the

- determination of local and global attribute weights

and the

- evaluation/ranking of pre-selected forecasting methods.

When the

- absolute measurement technique

is used the alternatives are compared against previously established scales rather than relative to one another as in the case of

- relative measurement.

\section{$2.1 \quad$ Modelling}

AHP based evaluation processes refer in most cases to hierarchically structured models that include a

- large number of evaluation criteria.

This holds also true for models concerning the evaluation of forecasting methods.

\subsubsection{Criteria Selection}

Case studies concerning forecasting methods show that the evaluation criteria can be assigned to three groups as indicated in Table 1.

Table 1. Evaluation criteria: Forecasting methods

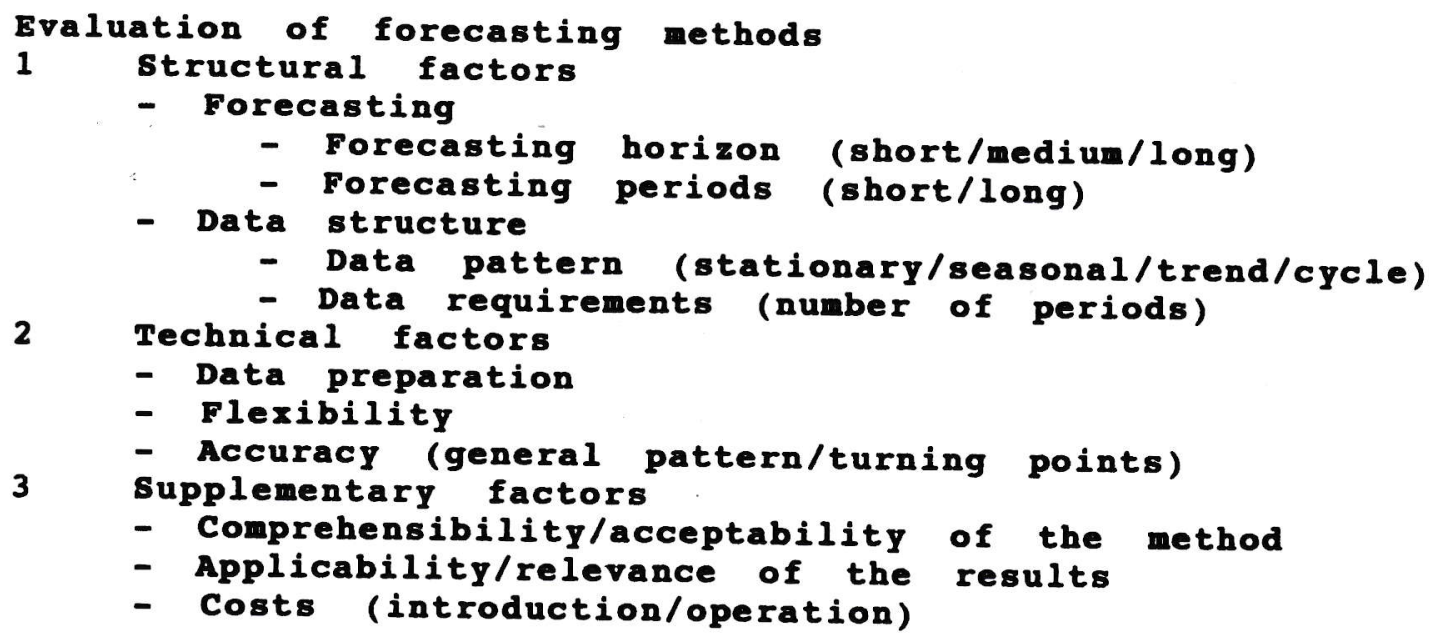


Structural criteria lead to a classification of forecasting methods according to the

- forecasting horzions and periods

as well as to the

- data structures involved in the analysis.

It is generally useful to consider three forecasting horizons (short/medium/long-term) and to differentiate between short/long forecasting periods. Additional criteria refer to the basic data patterns and the minimum data requirements.

\subsubsection{Technical Factors}

Technical criteria help to classify the forecasting methods with respect to the - need and type of data prepartions

as well as to the

- general flexibility of a method

which depends mainly on the possibility to analyse a variety of data patterns. Of central importance are the criteria relating to the

- accuracy of the forecasts

that depends on the suitability of a method to predict the general pattern of time series and to decern turning points.

\subsubsection{Suppiementary Factors}

The evaluation of forecasting methods has to be extended to a number of complementary - mainly psychological and economic - factors. They include the - comprehensibility and acceptability of the method and the

- applicability/relevance of the results

for specific needs of the users as well as the

- costs

connected with the introduction (hardware/software) and operation (manware) of the proposed forecasting technique.

\subsubsection{Model Presentation}

The hierarchical structure of the evaluation criteria can be represented in various graphical forms. They highlight the general embedment of the attributes within the general model.

\section{$2.2 \quad$ Weighting}

The weighting process starts with the

- determination of local and global priorities of the attributes

and leads to the

- evaluation and final ranking of pre-selected alternative forecasting methods. 


\subsubsection{Priority Weights for Attributes}

Priorities are set for criteria by comparing them in pairs with respect to the anchor element at the immediately higher level of the hierarchy using the standard (1-9) scale. For each set of pairwise comparisons, successive calculations lead to the determination of the local attribute weights (eigenvector of the comparison matrix) and some additional statistical measures (consistency index/ratio).

Figure 1 shows the priorities of the main criteria as a result of pairwise comparions with respect to the goal.

Figure 1. Determination of local priorities: Main criteria

$$
\text { Compare the relative IMPORTANCE with respect to: GOAL }
$$

Node: 0

1=EQUAL 3=MODERATE 5=STRONG 7=VERY STRONG 9=EXTREME

\begin{tabular}{|c|c|c|c|c|c|c|c|c|c|c|c|c|c|c|c|c|}
\hline 1 & STRUCTFA & 9 & 8 & 7 & 6 & 5 & 4 (3) 2 & 1 & 2 & 3 & 4 & 5) & \begin{tabular}{l|l}
6 & 7
\end{tabular} & 8 & 9 & TECHNIFA \\
\hline 2 & STRUCTFA & 9 & 8 & 7 & 6 & 5 & 4 (3) $2 !$ & 1 & 2 & 3 & 4 & 5 & \begin{tabular}{l|l}
6 & 7
\end{tabular} & 8 & 9 & SUPPLEFA \\
\hline 3 & TECHNIFA & 9 & 8 & 7 & 6 & 5 & 4) 3/2 & & 2 & 3 & 4. & 5 & & 8 & 9 & SUPPLEFA \\
\hline
\end{tabular}

\begin{tabular}{|l|l|}
\hline \multicolumn{1}{|c|}{ Abbreviation } & \\
\hline Goal & Evaluation of Forecasting Methods \\
\hline STTRUCTFA & Structural factors \\
\hline TECHNIFA & Technical factors \\
\hline SUPPLEFA & Supplementary factors \\
\hline
\end{tabular}

$$
\begin{array}{ll}
\text { STRUCTFA } & , 600 \\
\text { TECHNIFA } & , 200 \\
\text { SUPPLEFA } & , 200
\end{array}
$$

Inconșistency Ratiọ =0,0

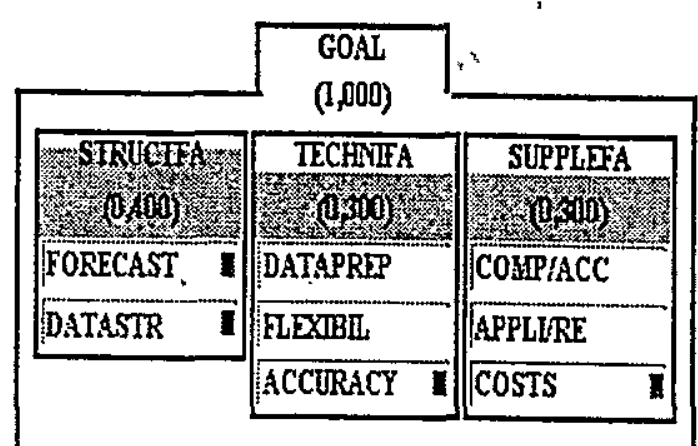

Similar calculations have to be made for the criteria on the lower hierarchical levels. A synthesis combines these priorities with respect to the goal. The global priorities at the lowest level are basic for the evaluation of the alternatives. 


\subsubsection{Pre-Selection and Rating of Alternatives}

The pre-selection of the forecasting methods presents no special problems. It is advisable to concentrate on pratice-oriented methods and to eliminate techniques and procedures that are of theoretical interest only (infeasible alternatives).

The selected alternatives are to be subjected to a general grading process by means of the

- absolute measurement technique.

In its simplest version it leads to the assignment of decimal numbers between 0 and 1 representing the fraction of the highest rating an alternative could receive under a specific basic criterion. .

The final ranking of the alternatives indicates that Exponential Smoothing is the most preferable technique under the set circumstances. See Figure 2.

Figure 2. Ranking of forecasting methods, partial view

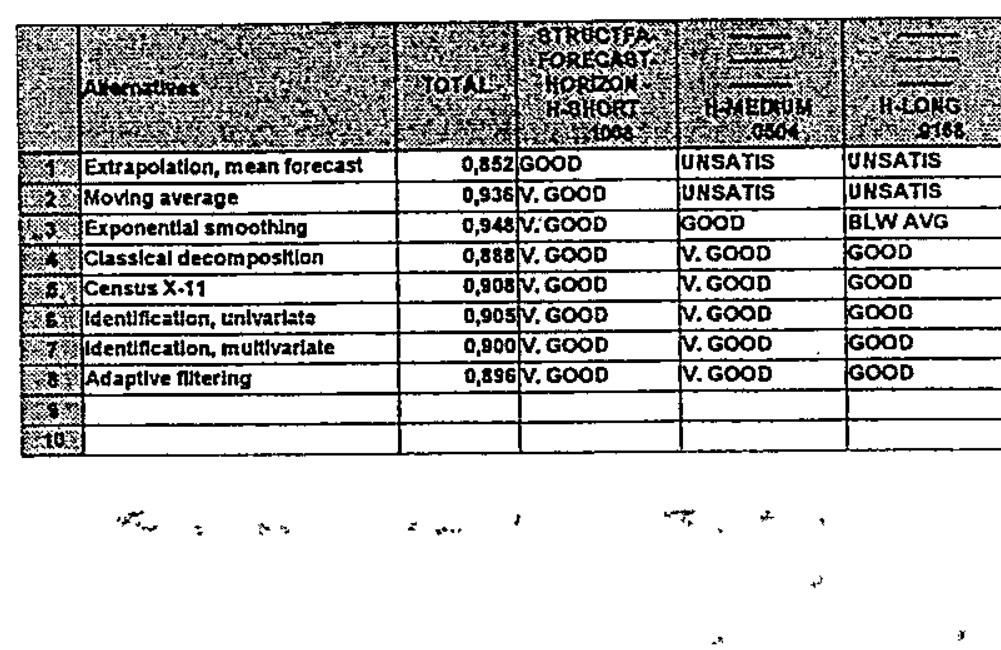

Based on these results the evaluation process coilid be repeated with respect to sectionalized subsets of the highest ranked alternative (such as linear exponential smoothing according to Holt/Brown/Winters/.). This approach is generally well accepted in practice and furthers cooperation with scientific advisors.

\section{$\therefore 3^{*}$ \\ 3 Selection of Förecasting Software}

The evaluation process strictly follows the standard AHP methodology.

3.1

Modelling

The model-building process is characterized by the inclusion of - software-supported forecasting methods and some additional

- input, output and system oriented criteria.

See Table 2 for details about the realized model structure.. 
Table 2. Evaluation criteria: Forecasting software

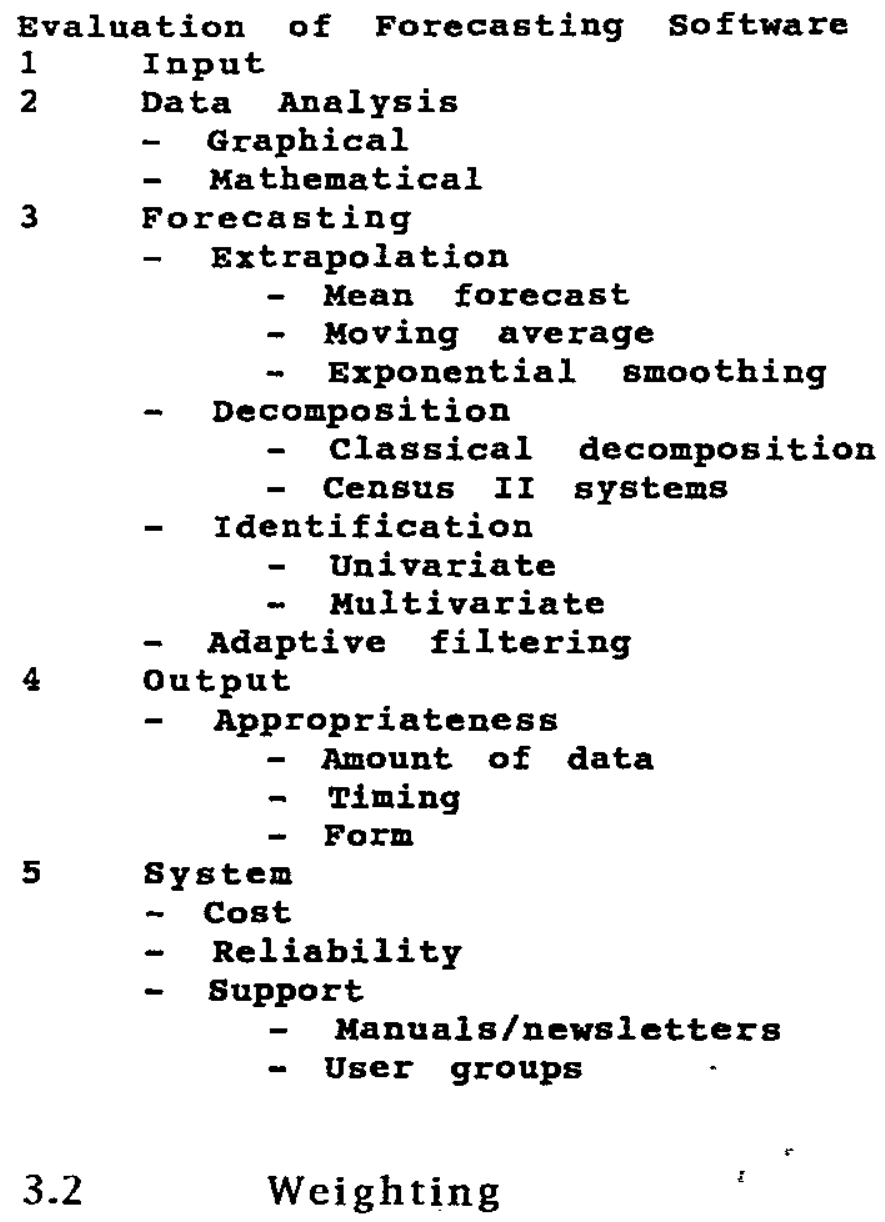

\subsection{Weighting}

The results of the attribute evaluation are partially shown in Figure 3 . The local priorities assigned to the forecasting methods in general (.600) and the extrapolation and exponential smoothing methods $(.650 ; .800)$ are bound to lead to a corresponding high global evaluation of the latter technique (.312). The global priorities of all the attributes considered in the evaluation process are shown in Table 3.

The weighting of the alternatives can be restricted to a

- small number of software packages.

They can be, selected on the basis of Software Reviews and other relevant sources that are periodically published in the American/European literature. Under such conditions, it is possible to use the

- relative measurement technique.

It is characterized by the determination of the priorities of (criteria, subcriteria and) alternatives by comparing them relative to each other rather than against a previously established (e.g., $0-1$ ) grading scale as in the case of absolute measurement.

In the current example the actual evaluation process has been limited to - three software packages.

See Figure 4 for a graphical representation of the final results of the evaluation process. 


\section{Summary and Conclusion}

The AHP methodology has been sucessfully used for the evaluation of forecasting methods and software in a number of case studies in various fields (sport and medical centers, pharmaceutical industry, etc.). The examples presented in this report have been adapted from these studies and simplified for the actual study. They clearly indicate that practice-oriented applications of the AHP methodology call for the use of adequate software systems such as - Expert Choice for Windows 9.0

or comparable products (AutoMan 2.0, Criterion DecisionPlus for Windows, etc.).

Figure 3. Local priorities of attributes, partial view
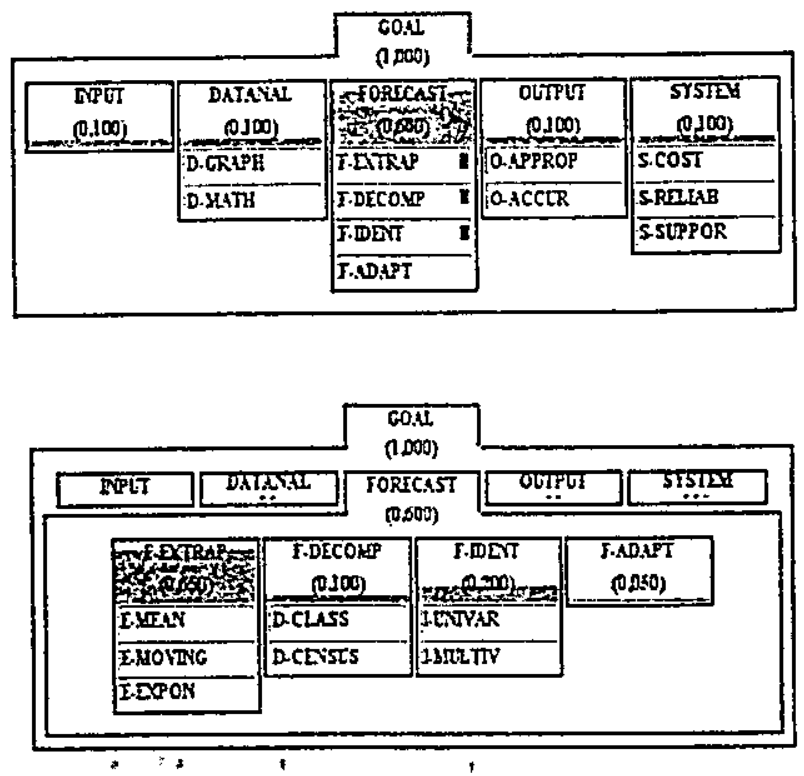

Table 3. Global priorities of attributes (with respect to, GOAL for , nodes below GOAL) .

ynthesis of Leaf Nodes with respect to GOAL

Distributive Mode

OVERALL INCONSISTENCY INDEX $=0,0$

\begin{tabular}{|c|c|c|c|c|}
\hline$\frac{\vdots}{\text { LEVEL }}$ & AEVEL 2 & $\because, ., \frac{!}{\text { LEVEL 3 }}$ & LEVEL 4 & LEVEL 5 \\
\hline \multicolumn{5}{|l|}{ INPUT } \\
\hline \multirow[t]{3}{*}{ DATANAL $=, 100$} & 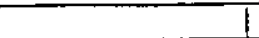 & & & $\because$ \\
\hline & D-GRAPH $=.030$ & & & $7 x$ \\
\hline & D-MATH $=070 !$ & & & \\
\hline \multicolumn{5}{|l|}{ FORECAST T $* 600$} \\
\hline & F.EXTRAP $=, 390$ & & & \\
\hline & & E.MEAN $=.020$ & * & \\
\hline & & E-MOVING $=.059$ & & \\
\hline$\because$ & & E.EXPON $=.312 \mid$ & & \\
\hline & F-DECOMP $=.060$ & & & \\
\hline & & D-CLASS $=, 003$ & & \\
\hline & & D-CENSUS $=.057$ & & \\
\hline & F-IDENT $=.120$ & & & . \\
\hline & & IUNNAR $=.102$ & & \\
\hline & & HMULTN $=018$ & 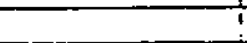 & \\
\hline & F-ADAPT $=.030$ & & & \\
\hline \multicolumn{5}{|l|}{ OUTPUT $=, 100^{\circ}$} \\
\hline & O-APPROP $=030$ & & & \\
\hline & OACCUR $=.070_{i}$ & & & \\
\hline \multicolumn{5}{|l|}{ SYSTEM $=.100$} \\
\hline & $\mathrm{S} \cdot \mathrm{COST}=, 020$ & & & \\
\hline & S-RELLA $=.070$ & & & \\
\hline & S-SUPPOR $=.010$ & & & \\
\hline
\end{tabular}


Figure 4. Performance sensitivity graph

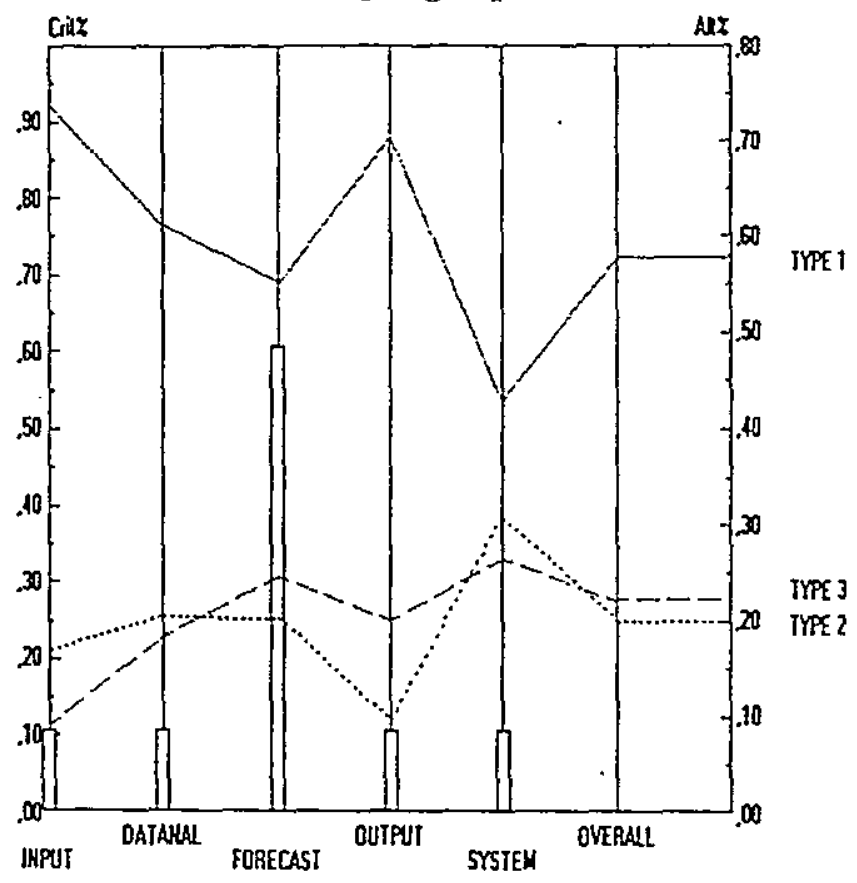

\section{References}

\begin{tabular}{|c|c|}
\hline Abbreviation & Definition \\
\hline INPUT & Input \\
\hline DATANGL & Ontingalysis \\
\hline FOARECAST & fortenstang \\
\hline OUTिUT & ontput \\
\hline SYSTEM & Syptom \\
\hline TYPE 1 & Software packego 1 \\
\hline TYPE 3 & 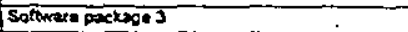 \\
\hline TYPE $\overline{2}$ & Sotweare packase 2 \\
\hline
\end{tabular}

Dyer, R. F. and Forman, E. H. (1991) An Analytic Approch to Marketing Decisions, Englewood Cliffs: Prentice Hall.

Expert Choice, Inc. (1995) Expert Choice for Windows Based on the Analytic Hierarchy Process. Version 9.0. User Manual, Pittsburgh: Expert Choice.

Expert Choice, Inc. (1995) Expert Choice. Decision Support Software. Version 9.0. Tutorial, Pittsburgh: Expert Choice.

Saaty, T. L.(1994) Fundamentals of Decision Making and Priority Theory with the Analytic Hierarchy Process, Pittsburgh: RWS Publications.

Saaty, T. L. (1990) Multicriteria Decision Making. The Analytic Hierarchy Process: Planning, Priority Setting, Resource Allocation, 2nd ed., Pittsburgh: RWS Publications.

Saaty, T. L and Vargas, L. G. (1994) Decision Making in Economic, Political, Social and Technological Environments: The Analytic Hierarchy Process, Pittsburgh: RWS Publications.

Weber, K. (1993) Mehrkriterielle Entscheidungen, München: Oldenbourg.

Weber, K. (1991) Prognosemethoden und -Software, Idstein: Schulz-Kirchner.

Weber, K. (1990) Wirtschaftsprognostik, München: Vahlen. 